Bioética

\section{BIOÉTICA E MORTE: RESPEITO AOS CADÁVERES}

Destacamos o uso polêmico de cadáveres apresentados por dois artigos publicados nos jornais:

I. Recall de cadáveres - uma universidade americana pediu de volta pedaços de cadáveres distribuídos para institutos médicos coma alegação destes não terem sido testados para Aids e hepatite!.

2. Utilização de cadáveres para um show público de dissecação e sua utilização, após transformação, em objetos de arte ${ }^{2}$.

O médico lida com a saúde do ser humano. A morte enquanto evento natural e inevitável a todos não cabe à Medicina. Cuidar da saúde significa cuidar do sofrimento humano. Já o sofrimento que pode advir frente à idéia de morte, este sim vai ser lidado pela Medicina e também pelas religiões.

A representação da morte está presente desde o início do ensino médico: o estudo através de cadáveres. Seguramente, a evolução da Medicina se deveu à possibilidade de ensino e pesquisa éticos em cadáveres. 0 estudo da anatomia só foi possível pelo fato de Leonardo da Vinci ter se dedicado ao estudo dos cadáveres, mesmo que sua finalidade fosse a aplicação na arte, além do conhecimento.

\section{Comentário}

Do ponto de vista da bioética, os cadáveres devem ser vistos como "res-humana" e não objetos quaisquer de uso, pelo significado afetivo da memória de um ser humano, principalmente para os indivíduos que com ele estabeleceram vínculos emocionais.

Entendemos que o fundamental em bioética é o respeito ao outro. Por exemplo, não basta o médico querer esclarecer a causa morte para se realizar uma necropsia pelo Serviço de Verificação de Óbitos (SVO), pode ser necessário que a família autorize esse procedimento.

No caso em questão do recall e de utilização dos cadáveres enquanto objetos de arte, entendemos que a questão ética se encontra justamente no consentimento dado pelo indivíduo antes da morte, ou após morte, pelos familiares, independentemente da finalidade da manipulação dos cadáveres, seja para transplante ou para criação de uma mostra artística.

$O$ respeito aos cadáveres por si é uma atitude religiosa, bem representado pelas "Missas ao Cadáver" celebradas nas escolas médicas. Já o sentido bioético da preocupação com o uso de cadáveres está no respeito aos seres humanos e no significado das relações que eles estabelecem, pois este não extingue com a morte de um indivíduo.

\section{Claudio Cohen \\ Gisele Gobbetti}

Referências

I. Agência REUTERS. Disponível em: URL:http://www.noticias.uol.com.br/inter/ reuters. Acesso em: 06 ago 2002.

2. BBC Brasil. Disponível em: http:// www.uol.com.br/bbc. Acesso em: I 3 fev 2002.

\section{Clinica Ciringica \\ Esôfago de BaRRETt. Prevalência, RISCO de adenocarcinoma e avaliaçäo ENDOSCÓPICA}

No departamento de Clínica Cirúrgica da Universidade de Pádua, na Itália, foi estudada a presença de metaplasia gástrica no esôfago distal. A definição do esôfago de Barrett foi modificada com o passar dos anos e apenas a metaplasia intestinal especializada tem demonstrado risco de desenvolvimento do câncer. A prevalência desta metaplasia em endoscopias com biópsias múltiplas, indicadas por sintomas dispépticos, varia de $9 \%-21 \%$ na cárdia e de I,2\%-8\% ao se avaliar $3 \mathrm{~cm}$ acima da transição esôfago-gástrica.

Entre os doentes com esôfago de Barrett, há uma prevalência no sexo masculino, entre a quinta e a sétima década de vida e o risco de se desenvolver adenocarcinoma ainda não é bem estabelecido, mas calcula-se que seja de 30 a 125 vezes maior que o da população geral. $O$ adenocarcinoma do esôfago é um tumor letal, com uma taxa de sobrevivência em cinco anos de $20 \%$. Até agora nenhum dos estudos prospectivos empregando a endoscopia mostrou qualquer impacto positivo nas taxas de sobrevivência dos doentes, mas a recomendação atual seria a de se monitorar doentes do sexo masculino, com boas condições gerais e com segmentos de esôfago de Barrett maiores que $3 \mathrm{~cm}$.

\section{Comentário}

Existem controvérsias para o diagnóstico desta doença, mas há uma preferência pela definição do epitélio de Barrett como apenas aquele que apresenta metaplasia intestinal especializada, que é o único tipo ligado à incidência aumentada de adenocarcinoma.

Aendoscopia pode sugerir a alteração, presente em cerca de $10 \%$ dos portadores de doença do refluxo, mas as biópsias são sempre necessárias para confirmar e aumentar a freqüência dos diagnósticos, detectando microfocos de metaplasia. A endoscopia com magnificação da imagem, recurso antes utilizado nas colonoscopias, passa aganhar destaquena avaliação desta afecção. $O$ exame endoscópico anual com múltiplas biópsias tem sido recomendado, mas esta recomendação não seria justificada na presença de epitélios colunares fúndico e cárdico. Oacompanhamento endoscópico pós-operatório mostra que o epitélio não se altera com o passar do tempo, sendo descritos doentes com degeneração adenocarcinomatosa após a correção do refluxo. Considera-se que $80 \%$ dos doentes operados para trataro refluxo gastroesofágico não apresentam regressão do epitélio colunar e novas opções de tratamento endoscópico, ainda em estudo, como a fotoablação com laser e a terapia fotodinâmica, que embora tenham resultados iniciais promissores, ainda esperam estudos a longo prazo para uma avaliação adequada.

Pedro luiz Squilacci leme Rodrigo Altenfelder Silva Otto-Michael Pius Höhne

Referências

I. Zaninotto G, Costantini M, Molena D, Rizzetto C, Ekser B, Ancona E. Barrett's esophagus. Prevalence, risk of adenocarcinoma, role of endoscopic surveillance. Minerva Chir 2002; 57: 819-36.

2. Prolla JC, Dietz J. Epitélio de Barrett. In: Marchesini JB, Malafaia O, editores. Doença do refluxo gastroesofágico. São Paulo: Atheneu; 1996.p.93-103.

3. Pollara WM. Conduta terapêutica no esôfago de Barrett. In: Marchesini JB, Malafaia O, 